\title{
Efficacy of platelet-rich plasma as a shielding technique after endoscopic mucosal resection in rat and porcine models
}

Authors

Institutions
Vicente Lorenzo-Zúñiga ${ }^{1,2}$, Jaume Boix ${ }^{1,2}$, Vicente Moreno de Vega ${ }^{1,2}$, Ignacio Bon ${ }^{1}$, Ingrid Marín ${ }^{1}$, Ramón Bartolí

${ }^{1}$ Endoscopy Unit, Hospital Universitari Germans Trias i Pujol, Badalona, Barcelona, Spain

${ }^{2}$ Centro de Investigación Biomédica en Red de Enfermedades Hepáticas y Digestivas (CIBEREHD), Barcelona, Spain submitted

10. March 2016

accepted after revision

23. May 2016

\section{Bibliography}

DOI http://dx.doi.org/

10.1055/s-0042-109170

Published online: 10.8.2016

Endoscopy International Open

2016; 04: E859-E864

(c) Georg Thieme Verlag KG

Stuttgart · New York

E-ISSN 2196-9736

\section{Corresponding author \\ Vicente Lorenzo-Zúñiga, \\ MD, PhD}

Endoscopy Unit

Department of

Gastroenterology/CIBERehd

Hospital Universitari Germans

Trias i Pujol

Carretera del Canyet s/n

08916 Badalona

Spain

Phone: +34-934978866

Fax: +34-934978946

vlorenzo.germanstrias@gencat. cat
Background and study aims: The aims were to assess the efficacy of endoscopic application of Platelet-rich plasma (PRP) to prevent delayed perforation and to induce mucosal healing after endoscopic resections.

Patients and methods: Colonic induced lesions were performed in rats $(n=16)$ and pigs $(n=4)$. Animals were randomized to receive onto the lesions saline (control) or PRP. Animals underwent endoscopic follow-up. Thermal injury was assessed with a 1-4 scale: (1) mucosal necrosis; (2) submucosal necrosis; (3) muscularis propria necrosis; and (4) serosal necrosis

Results: Saline treatment showed $50 \%$ of mortality in rats $(P=0.02)$. Mean ulcerated area

\section{Introduction \\ $\nabla$}

The risk of post-procedural adverse events increases with the size of the resected tumors [1]. To avoid this, shields of polyglycolic acid and fibrin [2] or clipping closure [3] have been tried. Because these techniques are time-consuming [2] or inefficient for covering large mucosal defects [3], new methods are needed.

Platelet-rich plasma (PRP) is a concentrate from blood that contains 3 to 5 times more platelet than the normal concentration [4]. The rationale behind using PRP is to stimulate platelets to secrete the anabolic growth factors they contain [5]. In this study we assessed the efficacy of endoscopic application of PRP as a shield, to prevent delayed perforation and to induce mucosal healing after colonic endoscopic resections with two animal models (rats and pigs). after 48 hours and 7 days was significantly smaller with PRP than with saline $(0.27 \pm 0.02$ $\mathrm{cm}^{2}$ and $0.08 \pm 0.01 \mathrm{~cm}^{2}$ vs. $0.56 \pm 0.1 \mathrm{~cm}^{2}$ and $\left.0.40 \pm 0.06 \mathrm{~cm}^{2} ; P<0.001\right)$. The incidence of thermal injury was significantly lower with PRP $(1.25 \pm 0.46)$ than in controls $(2.25 \pm 0.50) ; P=$ 0.006 . The porcine model showed a trend toward higher mucosal restoration in animals treated with PRP than with saline at weeks 1 and 2 (Median area in $\mathrm{cm}^{2}: 0.55$ and 0.40 vs. 1.32 and 0.79 )

Conclusions: Application of PRP to colonic mucosal lesions showed strong healing properties in rat and porcine models.

\section{Patients and methods \\ $\nabla$}

Animals

Sixteen male $400 \mathrm{~g}$ to $450 \mathrm{~g}$ on average SpragueDawley rats (Harlan Laboratories Models SL, Barcelona, Spain), and 4 female pigs weighing $35 \mathrm{~kg}$ to $40 \mathrm{~kg}$ (Specipig, Barcelona, Spain) were used in this study. All procedures were approved by the Institutional Animal Care and Use Committee of Hospital Universitari Germans Trias i Pujol (protocol number B9900005).

\section{Endoscopy}

Colonoscopes were performed with a gastroscope Evis Lucera 260 (Olympus, Tokio) with an outer diameter of $9.5 \mathrm{~mm}$, working channel $2.8 \mathrm{~mm}$. Room air was used for insufflation during the endoscopy.

\section{Preparation of PRP gel}

PRP was obtained by centrifugation of blood (2500 rpm/8 min) at room temperature (Olin-1, Olin SL, Barcelona, Spain). Withdrawal of peripheral blood was done in amounts of $4 \mathrm{~mL}$ in rats and $20 \mathrm{~mL}$ in pigs per animal. A $10-\mathrm{mL}$ syringe prefilled with acid citrate dextrose $(15 \% \mathrm{vol} / \mathrm{vol})$ 

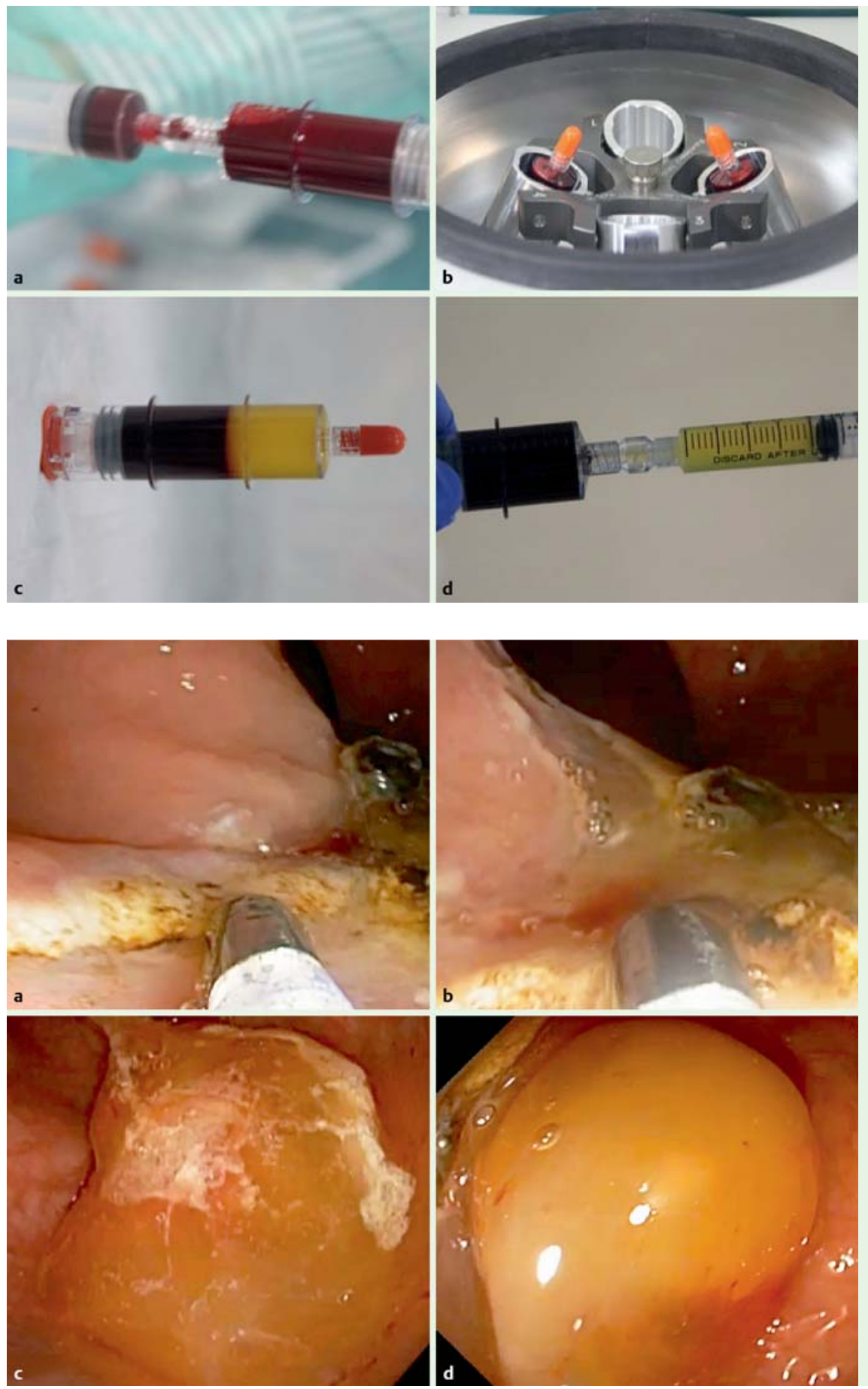

Fig. 1 Four-step method to obtain platelet-rich plasma (PRP). a Peripheral blood was drawn from each animal. b PRP was obtained by centrifugation of blood at room temperature. c Three different layers were obtained: erythrocytes at bottom, PRP in the middle, and platelet-poor plasma on the top. d PRP was filled into a syringe.

Fig. 2 Endoscopic shielding technique with platelet-rich plasma. a Tip of the catheter was positioned over the ulcer. b Activated PRP was gently sprayed onto the lesion. c Clot was formed after 1 to 2 minutes. $\mathbf{d}$ Clot was firmly adhered (after washing). was used. Syringes were centrifuged, obtaining 3 different layers: erythrocytes at the bottom, PRP and platelet-poor plasma (PPP) on the top ( Fig. 1). PRP was activated with the addition of 20 $\mathrm{mM} \mathrm{CaCl} 2$ just before administration. Activated PRP becomes a viscous solution after 3 to 5 minutes, as a solid clotted jelly mass.

\section{Shielding technique}

To perform endoscopic shielding technique (EST), healing coverage agents were applied over mucosal lesions with a catheter through the endoscopic working channel, covering as a shield the total surface of the ulcer. A volume of $1 \mathrm{~mL}$ in rats and $5 \mathrm{~mL}$ in pigs was applied to each animal. EST with PRP was performed positioning the tip of the catheter over the ulcer, then activated
PRP was gently sprayed onto the lesion, and after 1 to 2 minutes the clot was firmly organized ( $\bullet$ Fig. 2 ).

\section{Colonic induced lesions in rats}

After a 24-hour fasting period with free access to drinking water, rats were anesthetized by isoflurane inhalation (1.5\% with $98 \%$ $\mathrm{O}_{2}$ ) and placed in a supine position. Remaining feces were flushed away by injecting water through the anus. A drop of lubricating jelly (Aquagel; Ecolab, Leeds, England) was applied on the anal sphincter to facilitate insertion of the endoscope. The endoscope was then gently passed through the anus and further introduced under endoscopic vision. Water was injected through the endoscope's working channel to visualize the lumen of the colon. 


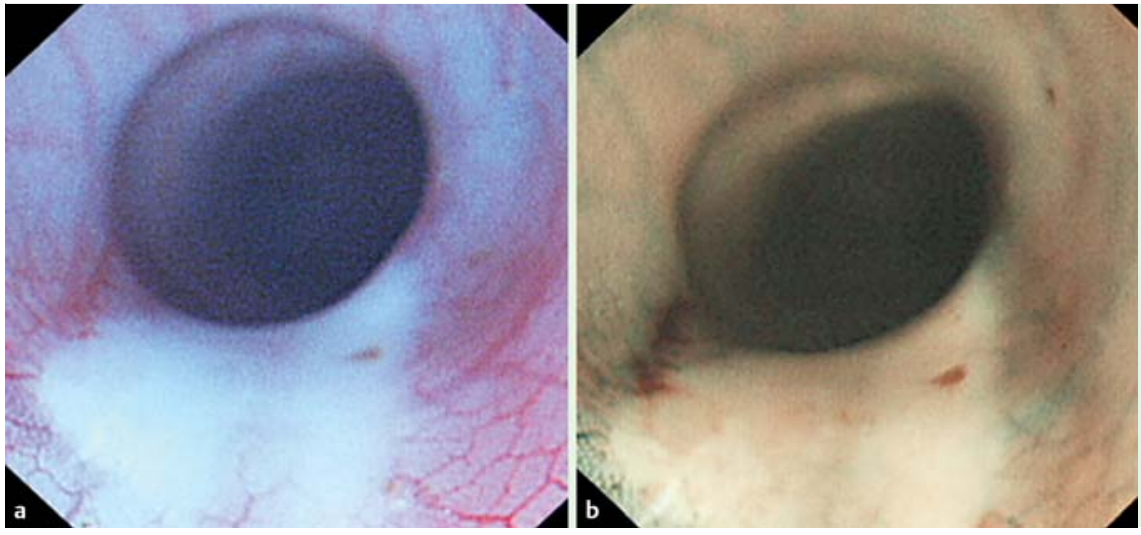

Fig. 3 Colonic induced lesions by Coagraspers Haemostatic Forceps in rat model $(40 \mathrm{~W} \times 4 \mathrm{sec})$ : Endoscopic view with high-resolution white-light imaging (left) and the corresponding narrowband image (right).

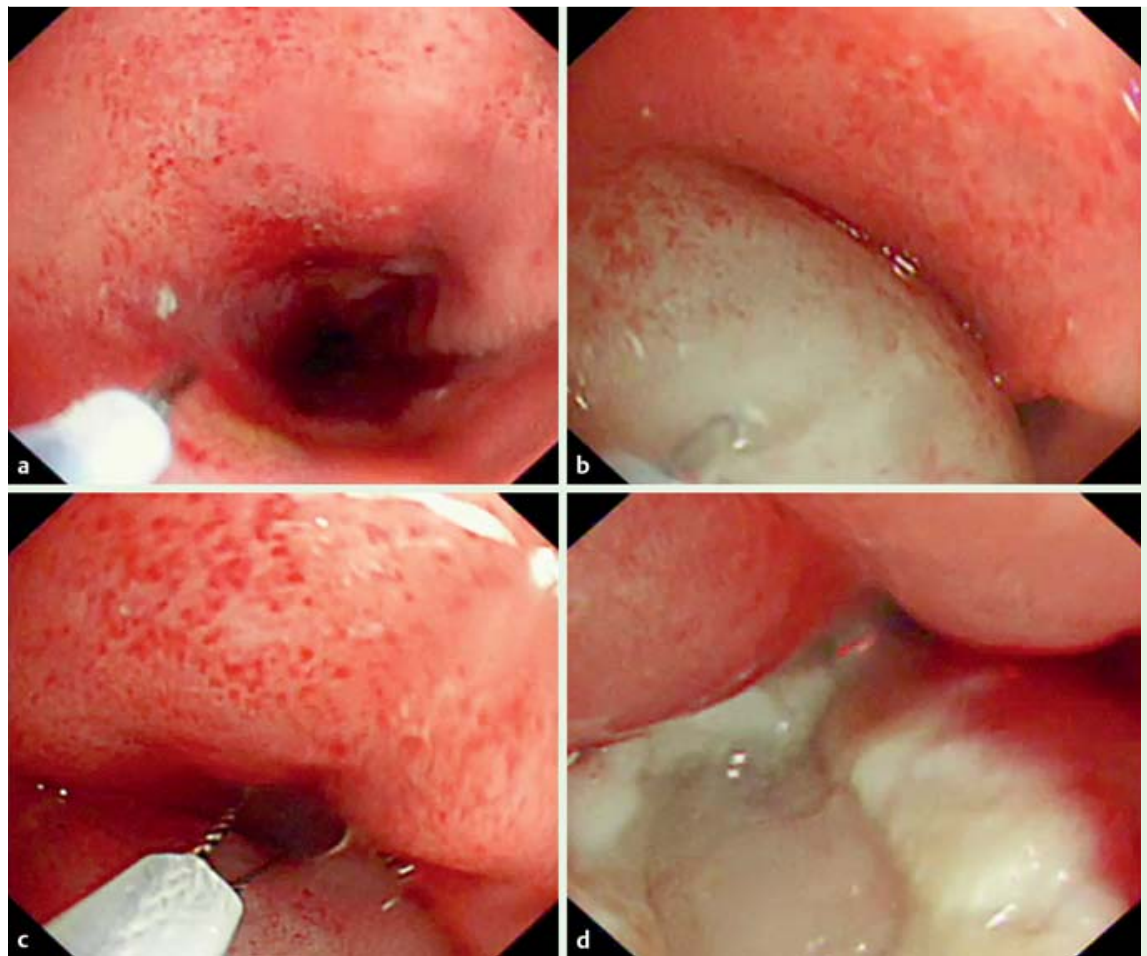

Fig. 4 Colonic EMR-induced lesions in porcine model. EMR was performed with snare polypectomy prior submucosal injection of saline.

Occasionally, the colon was inflated with air for better visualization of the lumen.

Colonic lesions were performed in the left colon, at $6 \mathrm{~cm}$ to the anal margin by Coagrasper Haemostatic Forceps (Olympus, Tokyo), with a power setting of $40 \mathrm{~W}$ over 4 seconds [6,7] ( $\bullet$ Fig.3). This technique produces deep thermal injury in the acute phase $(48 \mathrm{~h})$, with development of peritonitis in the late phase, 7 days after the damage. Animals were randomly divided into 2 groups $(\mathrm{n}=8)$ for EST with PRP and saline. Animals were allowed to eat after the intervention. Rats underwent endoscopic follow-up at 48 hours and 7 days after EMR, and were euthanized by anesthetic overdose.

After sacrifice, the colon was opened longitudinally to examine colonic mucosa. Full-thickness samples of approximately $4 \mathrm{~cm}$ were taken from the proximal left colon surrounding endoscopic lesions.

\section{Colonic EMR-induced lesions in pigs}

In the porcine model, food was not allowed 12 hours prior to the procedure. Preparation for colonoscopy was done with saline irrigation. Colonoscopy was performed under sedation with pro- pofol. Mucosal elevations were created at $25 \mathrm{~cm}$ to anal margin by submucosal injection of saline, then EMR with snare polypectomy and blended current was performed ( $\bullet$ Fig. 4 ). Animals were randomly allocated to EST with PRP or saline ( $\mathrm{n}=2$ each), and underwent endoscopic follow-up at 7 days and 14 days after EMR. Finally, pigs were euthanized and necropsied to obtain colonic samples as described above.

\section{Assessments}

Mucosal healing was evaluated as mean ulcerated area after 48 hours and 7 days in rats, and 7 days and 14 days in pigs. The mucosal healing rate was defined as a percentage of mucosal restoration. Measurement of mucosal lesion was performed comparing to the open forceps $(5 \mathrm{~mm})$ or by direct measurement with the specimen.

Thermal injury was evaluated with a 1 to 4 scale [6]: 1) mucosal necrosis; 2) submucosal necrosis; 3) transmural necrosis; and 4) peritonitis, microperforation, in hematoxylin and eosin $(\mathrm{H} \& \mathrm{E})$ histological sections using a conventional microscope (Olympus, Shinjuku-ku, Tokyo, Japan). 
Table 1 Mucosal healing and thermal injury in experimental model with rats treated with platelet-rich plasma (PRP) or saline.

\begin{tabular}{|c|c|c|c|}
\hline & $\begin{array}{l}\text { PRP group } \\
(n=8)\end{array}$ & $\begin{array}{l}\text { Saline group } \\
(n=8)\end{array}$ & $\begin{array}{l}\text { Test } \\
P \text {-value }\end{array}$ \\
\hline Mortality (\%) & 0 & 50 & 0.02 \\
\hline Basal ulcer $\left(\mathrm{cm}^{2}\right)$ & $0.41 \pm 0.03$ & $0.38 \pm 0.05$ & n.s. \\
\hline $\begin{array}{l}\text { Mean ulcerated area } \\
\text { at } 48 \text { hours }\left(\mathrm{cm}^{2}\right)\end{array}$ & $0.27 \pm 0.02$ & $0.56 \pm 0.1$ & $<0.001$ \\
\hline $\begin{array}{l}\text { Mean ulcerated area } \\
\text { at } 1 \text { week }\left(\mathrm{cm}^{2}\right)\end{array}$ & $0.08 \pm 0.01$ & $0.40 \pm 0.06$ & $<0.001$ \\
\hline Mucosal restoration (\%) & 80.5 & 2.4 & $<0.001$ \\
\hline Thermal injury & $1.25 \pm 0.46$ & $2.25 \pm 0.50$ & 0.006 \\
\hline
\end{tabular}

Values are given as mean \pm SD.

\section{Statistical analysis}

All data in rats are reported as the mean $\pm S D$, whereas in pigs as median. Statistical analyses were performed via unpaired student's t test with SPSS software version 14.0 (SPSS Inc, Chicago, Ill). A P value $<.05$ was considered statistically significant.

\section{Results}

$\nabla$

\section{Mucosal healing}

Delayed stricture or bleeding was not noticed in any animal included in the study. In rats, saline treatment showed $50 \%$ of mortality, being $0 \%$ with PRP $(P=0.02)$. Mortality was secondary to severe thermal injury with appearance of colon perforation in all animals. Basal ulcers were similar in both groups $(0.41 \pm 0.03$ $\mathrm{cm}^{2}$ with PRP vs. $0.38 \pm 0.05 \mathrm{~cm}^{2}$ with saline), but a significantly higher percentage of mucosal restoration was observed with PRP than with saline ( $80.5 \%$ vs. $2.4 \%$; $P<0.001$ ). Mean ulcerated area after 48 hours and 7 days was significantly smaller with PRP than with saline $\left(0.27 \pm 0.02 \mathrm{~cm}^{2}\right.$ and $0.08 \pm 0.01 \mathrm{~cm}^{2}$ vs. 0.56 $\pm 0.1 \mathrm{~cm}^{2}$ and $0.40 \pm 0.06 \mathrm{~cm}^{2} ; P<0.001$ ) ( $\bullet$ Table 1 ). Rats treated with PRP showed a strong healing activity at $48 \mathrm{~h}$ with high mucosal restoration at day 7 ( $\bullet$ Fig.5).
Table 2 Mucosal healing and thermal injury in porcine model treated with platelet-rich plasma (PRP) or saline.

\begin{tabular}{|lll|}
\hline & $\begin{array}{l}\text { PRP group } \\
(\mathbf{n = 2})\end{array}$ & $\begin{array}{l}\text { Saline group } \\
(\mathbf{n = 2})\end{array}$ \\
\hline Basal ulcer $\left(\mathbf{c m}^{2}\right)$ & 1.62 & 1.41 \\
\hline $\begin{array}{l}\text { Mean ulcerated area } \\
\text { at day 7 }\left(\mathrm{cm}^{2}\right)\end{array}$ & 0.55 & 1.32 \\
\hline $\begin{array}{l}\text { Mean ulcerated area } \\
\text { at day 14 }\left(\mathrm{cm}^{2}\right)\end{array}$ & 0.40 & 0.79 \\
\hline $\begin{array}{l}\text { Mucosal restoration (\%) } \\
\text { Thermal injury }\end{array}$ & 75.3 & 43.9 \\
\hline
\end{tabular}

Values are given as median

In pigs, PRP showed a trend toward higher mucosal restoration than did saline, at weeks 1 and 2 (median area in $\mathrm{cm}^{2}: 0.55$ and 0.40 vs. 1.32 and 0.79 ); $P=0.12$, respectively ( $\bullet$ Table 2 and - Fig.6). These data confirmed a higher mucosal healing rate with PRP than with saline, respectively (75.3\% vs. $43.9 \%$ ).

\section{Thermal injury}

Acute basal histologic assessment was not performed to avoid sacrifice of animals. EST with PRP induced a marked trend to less deep thermal injury in both studies. In rats, the incidence of thermal injury was significantly lower with PRP $(1.25 \pm 0.46)$ than with saline $(2.25 \pm 0.50) ; P=0.006$ ( $\bullet$ Table 1 ). Saline group showed necrosis of the muscularis propria and serosa on day 7 , whereas rats treated with PRP showed superficial necrosis without injury in muscularis propria ( $\bullet$ Fig. 7). In pigs, PRP was associated with a significant reduction in thermal injury ( $\square$ Table 2 ) and mucosal inflammation with partial restoration of the epithelium in Week 2 ( $\bullet$ Fig. 8).

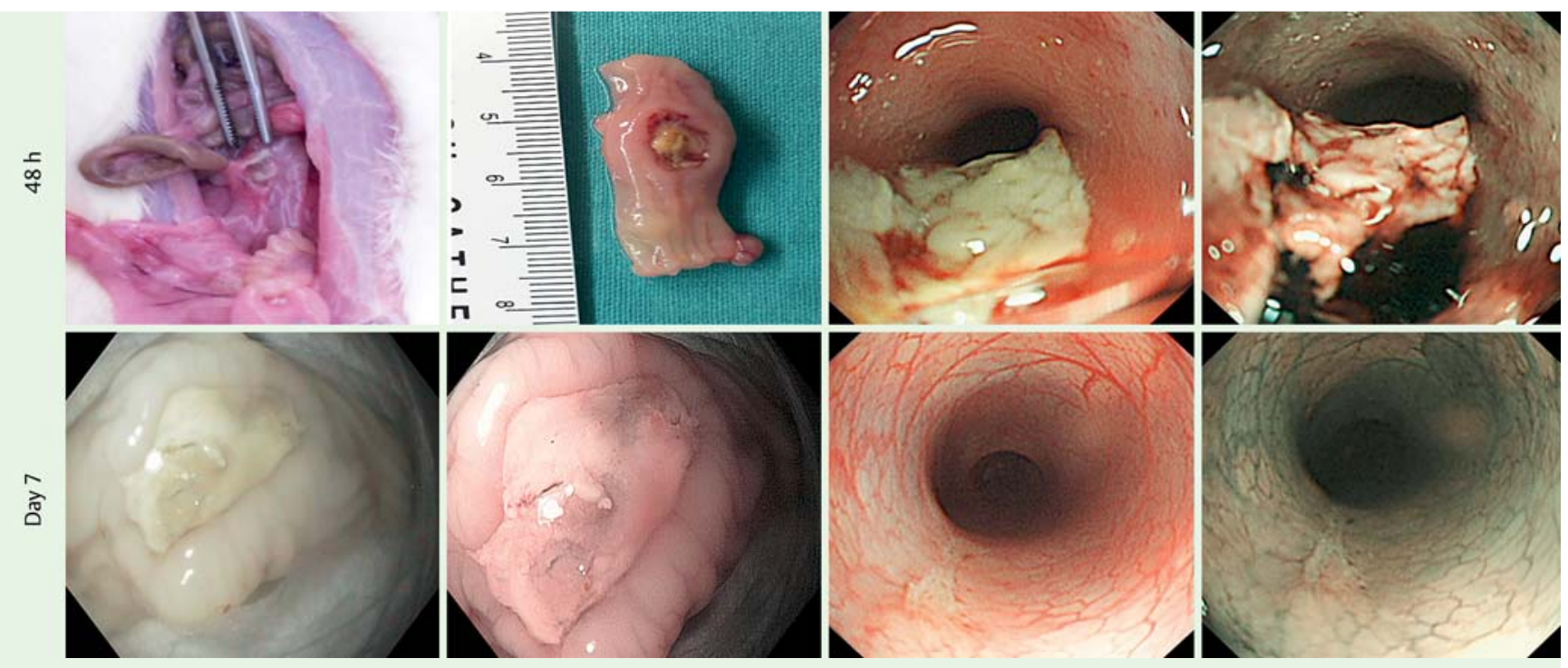

Fig. 5 Follow-up in both group of rats at 48 hours and 7 days. Macroscopic images (left) in saline group. Endoscopic follow-up (right) in animals treated with platelet-rich plasma. 


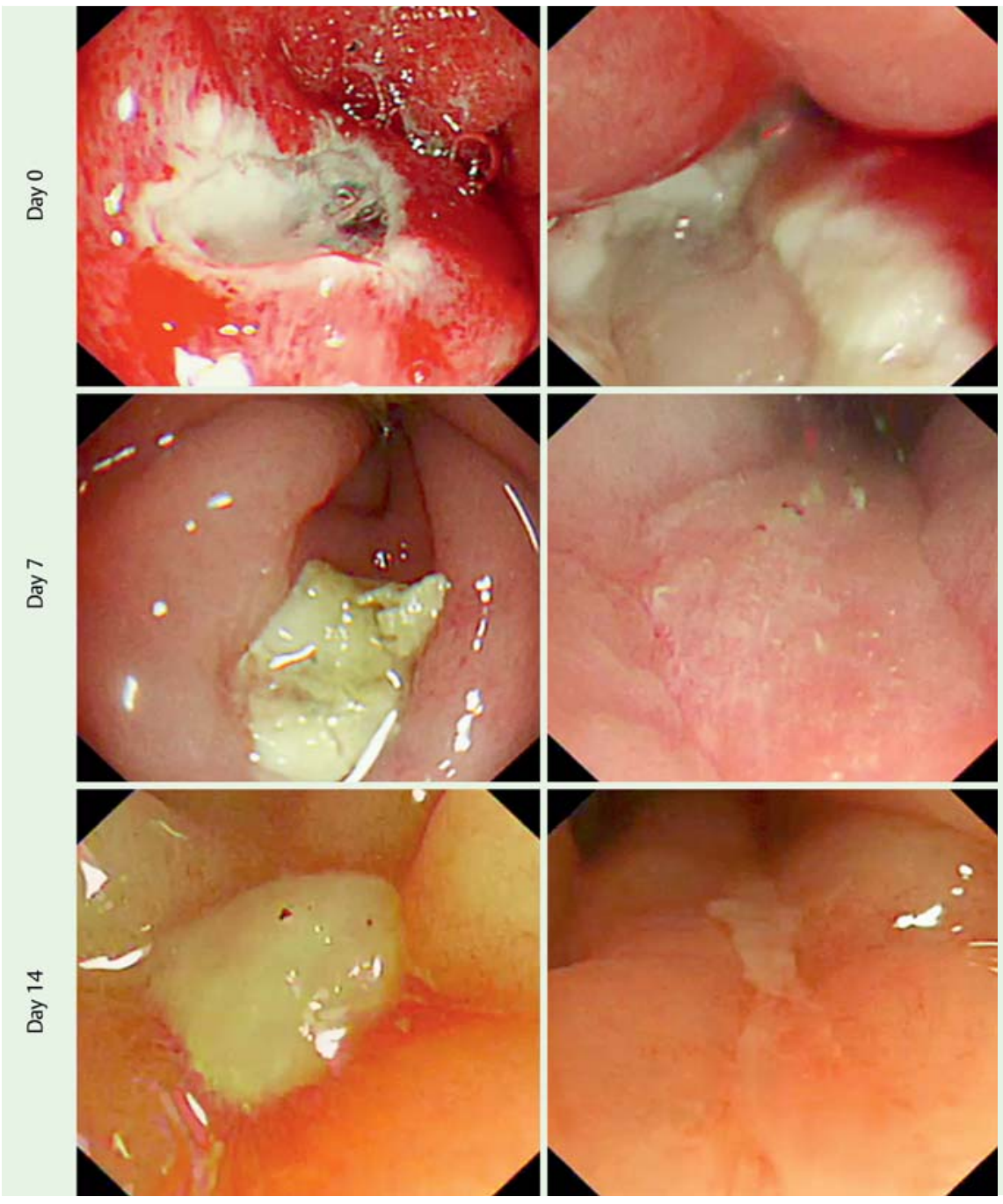

Fig. 6 Endoscopic follow-up in porcine model in both treated animals, saline (left) and platelet-rich plasma (right), at baseline, Day 7, and Week 2 of follow-up.

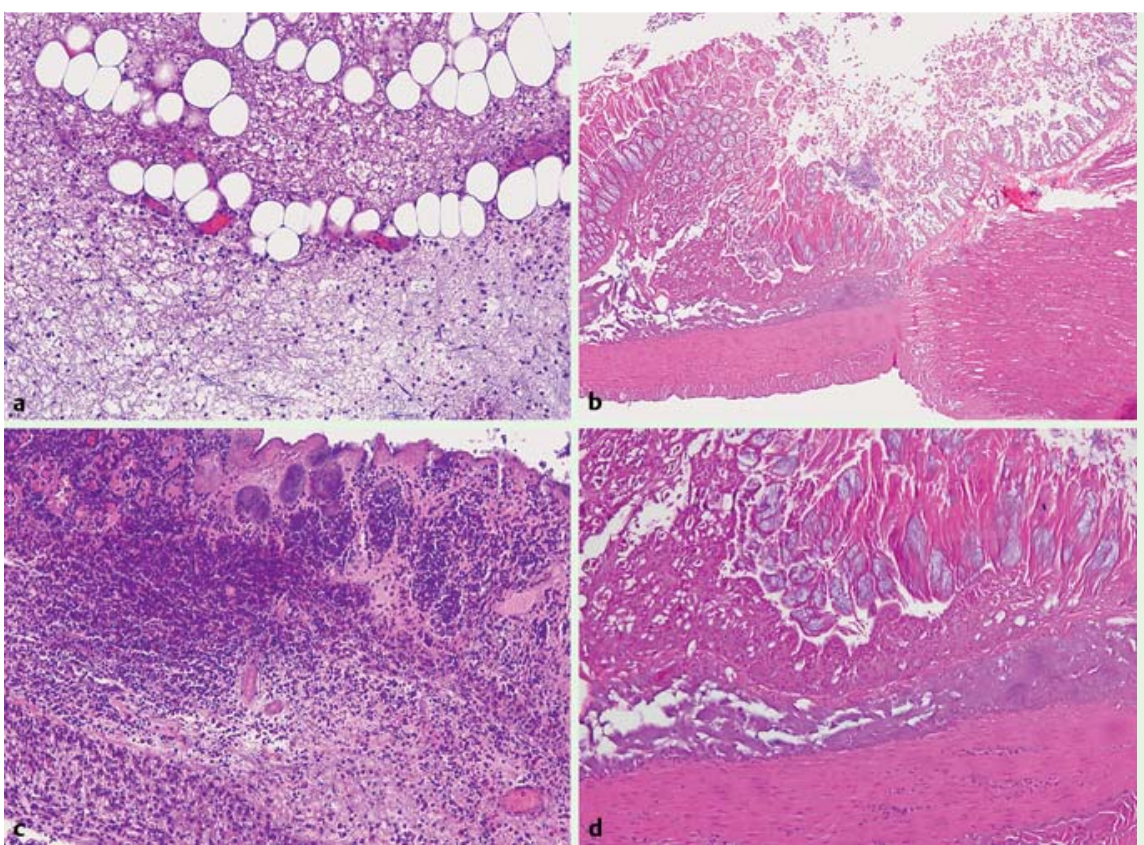

Fig. 7 Histologic study of colon sections with thermal injury in both groups of rats on Day 7. Saline group (left) shows necrosis of the muscularis propia and serosa. Rats treated with platelet-rich plasma (right) show superficial necrosis without injury in muscularis propria. 


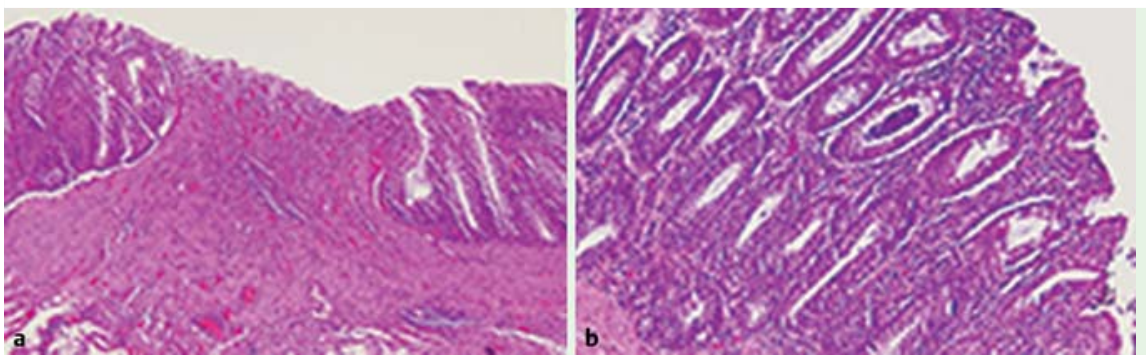

Fig. 8 Histologic study of colon sections with mucosal resection in both groups of pigs on Day 14 . Platelet-rich plasma treated group shows a significant reduction in mucosal inflammation with partial restoration of the epithelium (right), whereas saline group shows less reduction of mucosal inflammation and restoration (left).

\section{Discussion \\ $\nabla$}

This study showed that in both animal models, use of EST with application of PRP to endoscopic-induced mucosal lesions in the colon induced strong healing properties and reduced deep thermal injury. We need a way to prevent delayed perforation after large mucosal resections. One option is clip closure of the mucosal defect, but its use is limited to lesions smaller than $40 \mathrm{~mm}$ and the techniques can sometimes be complex [3]. The tissue-shielding method with polyglycolic acid sheets is promising approach, but it takes at least 35 minutes $[2,8]$.

Endoscopic and tomographic study of colon rats has been assessed by our group [7], as well as the proper method for preparing the colon before colonoscopy [9]. We have previously described an experimental model in rats that reproduces deep thermal damage in the colon, allowing application of endoscopic treatments, which showed that the muscular layer was thinner in the proximal left colon [6]. Our group has recently proposed performing EST with newly developed hydrogels that congeal over mucosal lesions after therapeutic endoscopy as a quick and safe technique for preventing delayed perforations after therapeutic endoscopy $[10,11]$.

PRP gel contains high levels of platelets, which release high quantities of key growth factors and recruits cells to the site of tissue damage for repair $[4,12]$, which is essential for physiologic mucosal healing. Recently, it has been reported that topical use of PRP gel promotes wound healing in primary colonic anastomosis [13]. Anabolic effects are directly correlated to platelet number [5], so we selected the PRP fraction of plasma to obtain better results. PRP preparation was carried out with a standardized protocol [14], where mean PRP platelet amount is about 4 to 5 times greater than that observed within peripheral blood samples.

Our study revealed that PRP has 2 beneficial effects: prevention of delayed perforation after therapeutic endoscopy and induction of mucosal healing after deep thermal injury. We initiated the experimental study with rats because those animals are widely used in research. A porcine model was selected to reproduce daily practice. EST with PRP has proven to avoid mortality in rats, because platelet clot acts as a shield with a mechanical defense associated with a thicker layer. We have also found, in both rat and porcine experimental models, that treating ulcers with PRP results in significantly faster and stronger healing of mucosa, with restoration of areas of deep thermal injury. Furthermore, PRP, as an inexpensive and easy-to-obtain gel, shows triple biological activity, hence it can be called a true "tri-bio" shield because it is bioadhesive, biodegradable, and bioactive.

Despite these promising results, our study has limitations because it is preclinical and preliminary. One of the most important criticism is that we do not have data on delayed bleeding or stric- tures, so we cannot evaluate the efficacy of PRP in prevention of these complications. Neither have we performed an acute histologic assessment of thermal injury and or evaluated the concentration of PRP in this protocol but data in those areas are available from previous studies.

In conclusion, EST with application of PRP to EMR-colonic mucosal lesions showed strong healing properties in rat and porcine models. These data suggest that EST may be a new and easy way to treat and manage mucosal lesions resulting from therapeutic endoscopy.

\section{Competing interests: None}

\section{References}

1 Paspatis GA, Dumonceau JM, Barthet $M$ et al. Diagnosis and management of iatrogenic endoscopic perforations: European Society of Gastrointestinal Endoscopy (ESGE) Position Statement. Endoscopy 2014; 46: $693-711$

2 Tsuji Y, Ohata K, Gunji T et al. Endoscopic tissue shielding method with polyglycolic acid sheets and fibrin glue to cover wounds after colorectal endoscopic submucosal dissection (with video). Gastrointest Endosc 2014; 79: 151 - 155

3 Zhang QS, Han B, Xu JH et al. Clip closure of defect after endoscopic resection in patients with larger colorectal tumors decreased the adverse events. Gastrointest Endosc 2015; 82: 904-905

4 Marx RE. Platelet-rich plasma: evidence to support its use. J Oral Maxillofac Surg 2004; 62: 489-496

5 Zhou B, Ren J, Ding C et al. Rapidly in situ forming platelet-rich plasma gel enhances angiogenic responses and augments early wound healing after open abdomen. Gastroenterol Res Pract 2013: 926764

6 Lorenzo-Zúñiga $V$, Boix J, Moreno-de-Vega $V$ et al. Microperforation of the colon: animal model in rats to reproduce mucosal thermal damage. J Surg Res 2014; 188: 415-418

7 Bartoli R, Boix G, Òdena G et al. Colonoscopy in rats: An endoscopic, histological and tomographic study. World J Gastrointest Endosc 2013; 5: $226-230$

8 Takimoto K, Toyonaga T, Matsuyama K. Endoscopic tissue shielding to prevent delayed perforation associated with endoscopic submucosal dissection for duodenal neoplasms. Endoscopy 2012; 44: E414-E415

9 Bartolí $R$, Boix J, Òdena $G$ et al. Determination of the ideal preparation for colonoscopy in a rat model. Surg Laparosc Endosc Percutan Tech 2012; 22: $542-545$

10 Bartolí R, Boix J, Moreno de Vega $V$ et al. Endoscopic Shielding Technique with a newly developed hydrogel on colonic microperforation in an experimental model with rats. UEG Journal 2015; 3: A554

11 Lorenzo-Zúñiga $V$, Bartolí $R$, Moreno de Vega $V$ et al. Endoscopic shielding technique with a newly developed hydrogel on mucosal thermal injury in a porcine model. UEG Journal 2015; 3: A560

12 Kazakos K, Lyras DN, Verettas D et al. The use of autologous PRP gel as an aid in the management of acute trauma wounds. Injury 2009; 40: $801-805$

13 Zhou B, Ren J, Ding C et al. Protection of colonic anastomosis with platelet-rich plasma gel in the open abdomen. Injury 2014; 45: 864-868

14 Amable PR, Carias RB, Teixeira MV et al. Platelet-rich plasma preparation for regenerative medicine: optimization and quantification of cytokines and growth factors. Stem Cell Res The 2013; 4: 67 